\title{
Pharmacist's Intervention and Medication Errors Prevention at Pediatrics, Obstetrics and Gynecology Hospital in East Province, Saudi Arabia
}

\author{
Amal Ahmad Alanazi ${ }^{1}$, Yousef Ahmed Alomi ${ }^{2} *$ (D), Mohammed Mohsen Almaznai ${ }^{3}$, Marzook \\ Aldwihi ${ }^{4}$,Ibrahim Abdul Karim Aloraifi ${ }^{5}$, Fatimah Ali Albusalih ${ }^{6}$ \\ ${ }^{1}$ Medication Safety Officer, Pharmaceutical Care Administration, Eastern Province, SAUDI ARABIA. \\ ${ }^{2}$ The Former General Manager of General Administration of Pharmaceutical Care, Former Head, National Clinical \\ Pharmacy and Pharmacy Practice, Former Head, Pharmacy R and D Administration, Ministry of Health, Riyadh, \\ SAUDI ARABIA. \\ ${ }^{3}$ Director of Pharmaceutical Care Administration in Eastern Province Health, SAUDI ARABIA. \\ ${ }^{4} 3$ Assistant director, Pharmaceutical Care Administration, Eastern Province, SAUDI ARABIA. \\ ${ }^{5}$ General Manager of Regional Health Affairs in Eastern Province, SAUDI ARABIA. \\ ${ }^{6}$ College of Clinical Pharmacy, Imam Abdulrahman Bin Faisal University (University of Dammam) Dammam, SAUDI \\ ARABIA.
}

\begin{abstract}
Objectives: Medication errors have a large impact on patient safety and on healthcare cost. Errors occur due to a combination of human and system-related failure. The pharmacist prevents all drug related problems. The objective of this study was to explore pharmacist intervention and prevented medication errors in Pediatrics, Obstetrics and Gynecology at a Tertiary Hospital in East Province, Saudi Arabia. Methods: This article describes 12 months retrospective cohort study of pharmacist intervention and prevented medication errors in year of 2015. This was a retrospective study conducted at 500-bed Pediatrics, Obstetrics and Gynecology in a Tertiary Hospital in East Province, Saudi Arabia. This system was a part of medication safety program. A tertiary hospital had medication safety officer with medication safety committee. All errors or unexpected events related with the medication system or a step in the medication process shall be reported using the medication error from/sheet. The form consisted of patient information, the sources of medication errors and qualification of committing errors. The type of medication errors, description of errors, causes of errors, approval to prevent the errors and the consequence of medication errors by using National Coordinating Council for Medication Error Reporting and Prevention (NCCMERP) system. Results: The total number of prevented medication errors were 1654 within 827 patients' prescriptions. The medication errors had been made by physicians followed by nurses. The sources of errors were general practitioner 631 (38.15\%) followed by consultant 554 (33.5\%). The most common error was made in Pediatrics (1-month to 6 years) followed by young adults (18-40 years). An occurred error, most of the time was afternoon 872 (52.72\%) errors followed by morning duty 685 (41.4\%) errors. The majority kind of mistakes were prescriber-related 1216 (73.52\%) followed by patient-related errors 426 (25.75\%). The outcome of medication error was 1651 (99.82\%) occurred which did not reach the patient. The most common medications involved in errors were Paracetamol syrup, iron tablet, folic acid tablet and calcium tablet. There were three errors for high-risk medication prohibited for instant: insulin, enoxaparin and heparin. Conclusion: This article presented the pharmacist's role in preventing medication errors, especially with pediatrics populations. Pharmacists have a crucial system-level role in planning and important medication safety programs and enhancement initiatives within health care organizations. The expanded role of pharmacists in preventing medication errors associated with patient safety programs and avoid the needless cost.

Key words: Pharmacist, Intervention, Errors, Prevention, Pediatrics, Obstetrics, Gynecology, East Province, Saudi Arabia.
\end{abstract}

Received: 6-10-2018;

Accepted: $20-12-2019$

*Correspondence to:

Dr. Yousef Ahmed Alomi

The Former General Manager of General Administration of Pharmaceutical Care, Former Head, National Clinical Pharmacy and Pharmacy Practice, Former Head, Pharmacy R and D Administration, Ministry of Health, P.O.BOX 100, Riyadh 11392, Riyadh, SAUDI ARABIA.

Phone no: +966504417712 Email: yalomi@gmail.com

DOI: 10.5530/ijpcs.2019.8.21

Copyright: ๑ the author(s),publisher and licensee International Journal of Pharmacology and Clinical Sciences. This is an open-access article distributed under the terms of the Creative Commons Attribution Non-Commercial License, which permits unrestricted noncommercial use, distribution, and reproduction in any medium, provided the original work is properly cited.

This is an open access article distributed under the terms of the Creative Commons Attribution-NonCommercial-ShareAlike 4.0 License

Access this article online

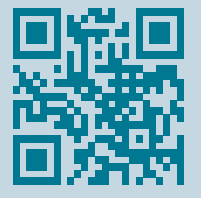

www.ijpcs.net 


\section{INTRODUCTION}

The role of the pharmacist has changed significantly in recent decades. Medication errors are a threat to patient safety. These errors reason for prolonged hospitalizations, extra medical interventions, indisposition and even death. Medication error is defined as any preventable event that may cause or lead to inappropriate medication use or patient harm while the medication is under the control of the health care professional, patient, or consumer. Medication Safety is defined as freedom from preventable harm with medication use. The goal of every health care organization in Ministry of Health (MOH) should be to constantly expand systems to avoid harm to patients due to common causes of medication errors. ${ }^{[1]}$ Health care organizations in $\mathrm{MOH}$ should monitor actual and potential medication errors that occur within their organization and investigate the root cause of errors with the goal of recognizing ways to advance the medication use system to prevent forthcoming medication errors and possible patient harm. Error reporting helps to understand why errors occur, to prioritize opportunities for error prevention and to generate long term improvements in patient safety. The focus on Medication safety start in the world in 1995 by the National Coordinating Council for Medication Error Reporting and Prevention (NCCMERP). The Council was formed to actively promote increased reporting, open communication, understanding and promotion of medication error prevention strategies through the coordinated efforts of member associations and agencies and to emphasis on ways to boost patient safety programs through a coordinated approach and a systems-based perception. Medication errors can also be categorized according to the severity of the consequences. The National Coordinating Council for Medication Error Reporting and Prevention (NCC MERP) classifies its medication error index into 9 categories: no error (category A), error and no harm (categories B-D), error and harm (categories E-H) and error and death (categories I). ${ }^{[2]}$

A study conducted by Kaushel $\mathrm{R}$ et al. ${ }^{[3]}$ on pediatrics population has found 616 of medical errors (out of 10,778 experiential medical doses; this represents $5.7 \%$ out of the whole observed doses. Another study, conducted by Wang JK et al. ${ }^{[4]}$ found 865 of medical errors (out of 16,938 investigated doses; this represents 5.2 out of each 100 prescriptions). This result is upsetting as the study was conducted at a large academic Tertiary hospital and specifically on pediatric inpatient settings. The present study found that pharmacists prohibited 3,089 medication errors occurred within 805 patients that means the number of medication errors prevented was 3.8 errors per each prescription. The study of Alagha HZ et al. ${ }^{[5]}$ has showed that there is, at least, once the prescription error in 1,107 medication orders. In addition, the researcher conducted a descriptive analysis of the Egyptian national online reporting system where they found that most of the common medication errors are related to prescription errors with $54 \%$ before monitoring, which represent $25 \%$ of the errors and $16 \%$ of errors caused by the administration. The study of Elden NMK, Ismail $\mathrm{A}^{[6]}$ revealed that most of the causes of medical errors occur during the ordering and prescription stage with $38.1 \%$. In addition, the study showed that $20.9 \%$ of the errors are due to administration-related practices. A recent study has found that each type of error was found to occur at various stages, though some more often during the packaging stages and the highest medication error rates were the missing clinical information (83.74\%) and miscommunication of drug order (80.9\%). The majority of medication errors occurred during prescribing drugs was $24.5-79 \%$ in pediatric practice. ${ }^{[7,8]}$ The most frequent class of medication error reported was anti-infective agent. ${ }^{[7]}$ Both of previous studies were completed at pediatric inpatient settings. The objective of this study was to explore pharmacist intervention and prevented medication errors at ambulatory care, emergency and inpatient sections in Pediatrics, Obstetrics and Gynecology in a Tertiary Hospital in East Province, Saudi Arabia.

\section{METHODS}

This article describes 12 months retrospective cohort analysis of pharmacist intervention and prevented medication errors in year of 2015 . This was a retrospective study conducted at department of Pediatrics, Obstetrics and Gynecology in a Tertiary Hospital in Dammam, Saudi Arabia. The hospital is formed of 5 floors and with 500 beds. This hospital uses outpatient clinics, inpatient departments, ambulance as well as pharmaceutical preparations room, mixing intravenous solutions, all pediatrics and adults' patient during the conduct of the study. The hospital provides clinical services in different specialties such as Endocrinology, Pediatrics, Hematology Pediatrics, Nephrology Pediatrics, Cardiology Pediatrics, Pulmonary pediatrics, The Neonatal Intensive Care Unit (NICU), The Pediatric Intensive Care Unit, Obstetrics and Gynecology in addition to ambulatory care services and emergency 
services. Also, the hospital pharmacy offers very comprehensive pharmaceutical services including inpatient pharmacy, ambulatory care pharmacy, intravenous admixture preparations, Total Parenteral Nutrition (TPN) services, pediatrics extemporaneous facilities and drug information services. Recently, the pharmacy department established medication safety program at East Province Region in 2013 and yet to start computerized physician order entry system. It was a part of National medication safety program of Ministry of Health and Central committee of medication committee and it headed by first author and second author membership. ${ }^{[9]}$ East Province Regional Medication safety committee established in 2013 headed by second author membership. In particular, a hospital medication safety program managed by part-time pharmacist and the program consisted of medication officer and local committee of medication safety. The officer monitors all medication errors, adverse drug reaction, drug quality system inside the hospital, local standard of accreditation body (Saudi Central Board of Health Care Accreditation) slandered, medication safety of Joint commission of Hospital accreditation from United States of America. ${ }^{[10,11]}$ And Institute Safety Medication Practice (ISMP) guidelines. ${ }^{[12-15]}$ They also felt responsible for medication safety course to all health care professional, physician, pharmacist, nurses etc. and report all medication safety related issues to higher administration and $\mathrm{MOH}$.

Medication officers are responsible for documenting Adverse Drug Events (ADEs) using the medication error form. All errors or unforeseen events related with the medication system or a step in the medication process shall be reported using the medication error notification form/medication error sheet whether or not the error reached the patient. The medical error form consists of 2 parts and 40 items including types and causes of medical errors. The form mainly consisted of patient information, description of errors - date and time, medical product involved in the event, impact of the error, consequences, intervention, the sources of medication errors and qualification of committing errors. Suspected medications, drug classification, stage of medication orders, details of reporter, route of administration for medication, the type of medication errors, description of errors, causes of errors, approval to prevent the errors and the consequence of medication errors by using National Coordinating Council for Medication Error Reporting and Prevention (NCCMERP) system. ${ }^{[2]}$ The study was conducted according to the ethics guidelines set out in the Declaration of Helsinki and written consent from was obtained from the institution. The Microsoft Excel sheet version 10.0 was used for data entry and analysis.

\section{RESULTS}

The total number of prevented medication errors were 1654 within 827 patients' prescriptions. The prevented medication errors had been made by physicians followed by nurses. The most common sources of errors were general practitioner $631(38.15 \%)$ and consultant 554 (33.5\%). The most common prevented error was made in Pediatrics (1-month to 6 years) 1128 (68.20\%) and young adults (18-40 years) 432 (26.12\%) (Table 1). The majority kind of prevented mistakes were prescriber-related $1216(73.52 \%)$ followed by patient-related errors $426(25.75 \%)$. The most common subtype of prevented medication errors was Wrong abbreviations 652 (53.62\%), Poor handwriting 561 (46.13\%) and Diagnosis not written 426 (100\%) (Table 2 and Table 3 ).

\begin{tabular}{|c|c|c|c|c|}
\hline \multicolumn{5}{|c|}{$\begin{array}{l}\text { No of Medication errors: } 1654 \\
\text { No of Patients } 827\end{array}$} \\
\hline No & \multicolumn{2}{|c|}{ Analysis Category } & Number & $\begin{array}{l}\text { Percent } \\
\text { ages }\end{array}$ \\
\hline \multirow{8}{*}{1} & \multirow{7}{*}{ Age of Patient } & 30 Days & 76 & $4.59 \%$ \\
\hline & & 1 month - 6 years & 1128 & $68.20 \%$ \\
\hline & & $6-12$ years & 18 & $1.09 \%$ \\
\hline & & $12-18$ years & 0 & $0.00 \%$ \\
\hline & & $18-40$ years & 432 & $26.12 \%$ \\
\hline & & $40-65$ years & 0 & $0.00 \%$ \\
\hline & & more than 65 years & 0 & $0.00 \%$ \\
\hline & & Total & 1654 & $100.00 \%$ \\
\hline \multirow{5}{*}{2} & \multirow{4}{*}{$\begin{array}{l}\text { Source of } \\
\text { Medication Error }\end{array}$} & Physician & 1648 & $99.64 \%$ \\
\hline & & Pharmacist & 0 & $0.00 \%$ \\
\hline & & Nurses & 6 & $0.36 \%$ \\
\hline & & Others & 0 & $0.00 \%$ \\
\hline & & Total & 1654 & $100.00 \%$ \\
\hline \multirow{4}{*}{3} & \multirow{3}{*}{$\begin{array}{l}\text { Qualification } \\
\text { of committing } \\
\text { Errors }\end{array}$} & GP & 631 & $43.58 \%$ \\
\hline & & Specialist & 263 & $18.16 \%$ \\
\hline & & Consultant & 554 & $38.26 \%$ \\
\hline & & Total & 1448 & $100.00 \%$ \\
\hline
\end{tabular}

\begin{tabular}{|l|c|c|}
\hline \multicolumn{3}{|c|}{ Table 2: Type of medication errors preventions. } \\
\hline Elements & Numbers & Percentages \\
\hline Patient-Related error & 426 & $25.75 \%$ \\
\hline Prescriber-Related and general errors & 1216 & $73.52 \%$ \\
\hline Drug-Related errors & 10 & $0.6 \%$ \\
\hline Dosage form-Related errors & 0 & $0 \%$ \\
\hline Therapeutics-related errors & 2 & $0.13 \%)$ \\
\hline Total & 1654 & \\
\hline
\end{tabular}




\begin{tabular}{|c|c|}
\hline Patient-Related error & $N(\%)$ \\
\hline Diagnosis not written & $426(100 \%)$ \\
\hline Patient allergy & $0(0 \%)$ \\
\hline Patient body weight not written & $0(0 \%)$ \\
\hline Patient age not written & $0(0 \%)$ \\
\hline Wrong patient & $0(0 \%)$ \\
\hline Non- existing patient & $0(0 \%)$ \\
\hline Total & 426 \\
\hline Prescriber-Related and general errors & $\mathrm{N}(\%)$ \\
\hline Prescriber name is missing /unclear & $0(0 \%)$ \\
\hline Prescriber ID\# is missing /unclear & $0(0 \%)$ \\
\hline Prescriber signature missing / unclear & $0(0 \%)$ \\
\hline Prescriber not follow policy of prescribing (write dose, weight) & $3(0.25 \%)$ \\
\hline Department is missing / unclear & $0(0 \%)$ \\
\hline Poor handwriting & $561(46.13 \%)$ \\
\hline Wrong abbreviations & $652(53.62 \%)$ \\
\hline Prescription data unclear & $0(0 \%)$ \\
\hline Total & 1216 \\
\hline Drug-Related errors & $N(\%)$ \\
\hline Incorrect dose-overdosing & $6(60 \%)$ \\
\hline Dose omitted & $1(10 \%)$ \\
\hline Duration-inadequate & $0(0 \%)$ \\
\hline Dosing frequency-excessive & $1(10 \%)$ \\
\hline Incorrect dose-under dosing & $0(0 \%)$ \\
\hline Amount of drug missing / unclear / insufficient & $0(0 \%)$ \\
\hline Drug name is missing /incorrect & $0(0 \%)$ \\
\hline Duration-excessive & $0(0 \%)$ \\
\hline Dosing frequency-inadequate & $0(0 \%)$ \\
\hline IV drug without labeling & $1(10 \%)$ \\
\hline Incorrect drug & $1(10 \%)$ \\
\hline Total & 10 \\
\hline Dosage Form-Related Errors & $N(\%)$ \\
\hline Incorrect /unclear formulation & $0(0 \%)$ \\
\hline Incorrect / unclear route & $0(0 \%)$ \\
\hline Incorrect / unclear strength & $0(0 \%)$ \\
\hline Total & 0 \\
\hline Therapeutics-Related Errors & $N(\%)$ \\
\hline Drug-drug interaction & $0(0 \%)$ \\
\hline Drug-Disease interaction & $0(0 \%)$ \\
\hline Therapeutic duplication & $2(100 \%)$ \\
\hline Total & 2 \\
\hline
\end{tabular}

An occurred error, most of the time was afternoon 872 (52.72\%) errors followed by morning duty 685 (41.4\%) errors. The most of prevented Medication administration errors were oral 1201 (76.84\%) followed by Intravenous $113(7.23 \%)$ and Nose administration $113(7.23 \%)$. The most package container error was the Bottle packaging 1371 (90.44\%) and Multi-dose vial 88 (5.80\%). The most common preventable medication errors were near miss an error occurred but did not reach to the patients 1651 (99.82\%) followed by errors reached to the patient without any harm $3(0.18 \%)$ (Table 4). The most common medications involved in errors were Paracetamol syrup, Iron tablet, Folic acid tablet and Calcium tablet. There were three errors for high-risk medication prohibited for instant: insulin, enoxaparin and heparin (Table 5).

\section{DISCUSSION}

Much has been written on the importance of medication errors in pediatrics and in precise on medication errors. The MOH's Medication Safety Program starts to arise in 2013. ${ }^{[1]}$ The program aims to eliminate or reduce the medication errors and prevent harms from reaching the patients. It can be reached through building safer organization endlessly improve its quality. The medication safety manual, which is considered as the foundation of the program, was the first step to be formulated to serve as guide for $\mathrm{MOH}$ organizations. There are medication safety officers, as well as there is a committee to medication safety in both the hospitals, primary health care and the Committee for each region as well as the main committee meets monthly in the ministry's pharmaceutical care administration. For the eastern region, there are 10 hospitals containing medication safety officer, medication safety committee, ISMP medication safety for hospitals in 2014, medication safety committee in the region to analyze the study to develop plans and prevent their reoccurrence. In 2015, basic medication safety course was started in maternity children hospital, Dammam, where 42 nurses, 9 doctors and 7 pharmacists were the highest attendees. Medication error is an essential variable to determine patient safety services, so it is crucial to realize the weak points of health care members regarding medication error and provide an educational program to resolve them.

The aim of the study is to explore learning outcome of medications safety program with emphasis of medications error prevention. The mean number of medication errors committed through physicians because the most frequent type of error occurred during prescribing errors and only by law in Saudi Arabia, the physicians had prescribing authority. The similar 


\begin{tabular}{|c|c|c|c|c|}
\hline & & & $\begin{array}{l}\frac{\vdots}{\Phi} \\
\frac{8}{E} \\
z\end{array}$ & 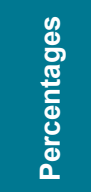 \\
\hline \multirow{4}{*}{4} & \multirow{4}{*}{ Time of Error } & Morning 7:30am-3:30pm & 685 & $41.46 \%$ \\
\hline & & Afternoon 3:30pm-11:30pm & 872 & $52.78 \%$ \\
\hline & & Night 11:30pm-7:30am & 95 & $5.75 \%$ \\
\hline & & Total & 1652 & $100.00 \%$ \\
\hline \multirow{13}{*}{5} & \multirow{13}{*}{$\begin{array}{l}\text { Route of } \\
\text { Administration }\end{array}$} & Oral & 1201 & $76.84 \%$ \\
\hline & & Eye & 11 & $0.70 \%$ \\
\hline & & Ear & 7 & $0.45 \%$ \\
\hline & & Nose & 113 & $7.23 \%$ \\
\hline & & Inhalation & 2 & $0.13 \%$ \\
\hline & & IV & 113 & $7.23 \%$ \\
\hline & & IM & 37 & $2.37 \%$ \\
\hline & & IT & 0 & $0.00 \%$ \\
\hline & & $\mathrm{sc}$ & 0 & $0.00 \%$ \\
\hline & & Topical Skin & 4 & $0.26 \%$ \\
\hline & & Rectal & 75 & $4.80 \%$ \\
\hline & & Others & 0 & $0.00 \%$ \\
\hline & & Total & 1563 & $100.00 \%$ \\
\hline \multirow{9}{*}{6} & \multirow{9}{*}{$\begin{array}{l}\text { Package } \\
\text { Container }\end{array}$} & Unit Dose & 10 & $0.66 \%$ \\
\hline & & Syringe & 37 & $2.44 \%$ \\
\hline & & Bottle & 1371 & $90.44 \%$ \\
\hline & & Single Dose Vial/ Ampoule & 1 & $0.07 \%$ \\
\hline & & Multi Dose Vial & 88 & $5.80 \%$ \\
\hline & & IV Piggy Bag & 8 & $0.53 \%$ \\
\hline & & Intravenous Solution & 1 & $0.07 \%$ \\
\hline & & Others & 0 & $0.00 \%$ \\
\hline & & Total & 1516 & $100.00 \%$ \\
\hline \multirow{10}{*}{7} & \multirow{10}{*}{$\begin{array}{l}\text { Outcome of } \\
\text { Error }\end{array}$} & A (Potential Risk) & 0 & $0.00 \%$ \\
\hline & & B (Near miss) & 1651 & $99.82 \%$ \\
\hline & & c & 3 & $0.18 \%$ \\
\hline & & D & 0 & $0.00 \%$ \\
\hline & & E & 0 & $0.00 \%$ \\
\hline & & $\mathrm{F}$ & 0 & $0.00 \%$ \\
\hline & & G (SE) & 0 & $0.00 \%$ \\
\hline & & $H(S E)$ & 0 & $0.00 \%$ \\
\hline & & I (SE) & 0 & $0.00 \%$ \\
\hline & & Total & 1654 & $100.00 \%$ \\
\hline
\end{tabular}

findings reported by Cunningham $\mathrm{KJ}$ and Kaushal $\mathrm{R}$ et al. ${ }^{[6,7]}$ during their study. Medical errors committed by residents have inadequate disclosure to senior

\begin{tabular}{|c|c|c|}
\hline NO & Medication & Number \\
\hline 1 & Paracetamol syp & 220 \\
\hline 2 & Iron tab & 210 \\
\hline 3 & Folic acid tab & 210 \\
\hline 4 & Calcium tab & 210 \\
\hline 5 & Chloropheniramine syp & 170 \\
\hline 6 & Normal saline drop & 120 \\
\hline 7 & Insulin inj & 108 \\
\hline 8 & Augmentin susp & 91 \\
\hline 9 & Paracetamol supp & 77 \\
\hline 10 & Diphenhydramine syp & 63 \\
\hline 11 & Oral rehydration solution & 53 \\
\hline 12 & Clexane inj & 37 \\
\hline 13 & Vit D3 drop & 17 \\
\hline 14 & Gentamycin drop & 13 \\
\hline 15 & Actifed syp & 11 \\
\hline 16 & Amoxacillin susp & 7 \\
\hline 17 & Ventolin Buff & 4 \\
\hline 18 & Fucidin oint & 4 \\
\hline 19 & Erythromycin susp & 2 \\
\hline 20 & Gentamycin inj & 2 \\
\hline
\end{tabular}

physicians. Unfortunately, very few residents have been taught how to disclose the error and majority do not have proper experience of disclosing an error. Trainees often choose not to disclose their medical errors to their senior physicians or supervisors. However, potential errors-those errors not causing harm-occurred in pediatric patients more often than in adults. ${ }^{[6]}$ The current study was conducted among ambulatory care and few from inpatient settings, while the previous study was conducted among inpatient settings. ${ }^{[6]}$

The prescribing stage is one of the stages where medication errors occur most frequently. The most common factors related with errors at this stage have been cited as lack of knowledge pertaining to both the drug prescribed and the patient for whom the drug is prescribed. Prevention of errors at the prescribing stage is one of the important steps towards reducing medication errors with emphasis of wrong used of abbreviations or poor handwriting or patient related errors. The similar findings reported by Cunningham KJ. ${ }^{[7]}$ The potential of errors occurred during morning or evening duty. The morning duty is normal with regular days, while evening duty associated with emergency visitors. Pediatric patients are more susceptible to 
medication errors for a variety of reasons including physical and social differences and the necessity for patient-specific dosing. Patients used oral pediatrics formulations and most of medication errors occurs at ambulatory care or emergency pharmacy in this study. Kaushal R et al. study analyses different research setting parenteral medication dispensing from mostly inpatient settings more than outpatient settings. ${ }^{[6]}$ Preventable medication errors contribute substantially to healthcare cost, not reached to the pharmacist or didn't cause harm or didn't reach the patient and there is not death case. The most common type of error was wrong administration such as Paracetamol for pediatrics usage or two medications for pregnant lady's as received for instance folic and calcium. Kaushal $\mathrm{R}$ et al. showed anti-infective agent was the most frequent class of medication error reported because difference in the research site as well as inpatient settings, while current study was conducted among mostly ambulatory care settings. ${ }^{[6]}$ The study showed some high-risk medications prevented mistakes. High-risk medications have the potential to cause significant patient harm or even death when used mistakenly. Special safeguards are in place in most healthcare institutions to minimize the risk of errors associated with these medications as per the new regulations of medications management of Saudi Board of Health care institution accreditation. [16] The medications safety program is very essential in the pharmacy practice. The program impact was very critical benefit to the patient care. The medications safety program should increase and implement to all $\mathrm{MOH}$ hospitals in the Kingdom of Saudi Arabia.

\section{CONCLUSION}

Pediatric medication errors can be reduced through multiple interventions aimed at improving the medication process. Further research is needed in the areas of ambulatory patients, non-developed countries, administering and dispensing errors and community hospitals and should use identical definitions for medication errors and outcomes. Basic medication safety course is essential for all pediatrician working at healthcare institutions. Additional cost-effectiveness data on interventions and preventions to diminish pediatric medication errors would advantage policy makers and medical leaders as they choose between multiple possible interventions. Reducing medication errors offerings an important occasion for refining the quality and variety of current research. Expanding of pediatrics medication safety program is highly recommended at hospitals in Kingdom of Saudi Arabia.

\section{ACKNOWLEDGEMENT}

None.

\section{CONFLICT OF INTEREST}

The authors decare no conflict of interest.

\section{ABBREVIATIONS}

MEs: Medication Errors; UK: United Kingdom; MOH: Ministry of Health; ISMP: Institute Safety Medication Practice; NCC: National Coordinating Council; MERP: Medication Error Reporting and Prevention; KSA: Kingdom of Saudi Arabia.

\section{ORCID ID}

Yousef Ahmed Alomi (D), https://orcid.org/0000-00031381-628X

\section{REFERENCES}

1. Alomi YA. National Medication Safety Program at Ministry of Health in Saudi Arabia. J Pharmacol Clin Res. 2017;3(2):1-7.

2. Hartwig SC, Denger SD, Schneider PJ. Severity-indexed, incident report-based medication error-reporting program. Am J Hosp Pharm. 1991;48(12):2611-6.

3. Kaushal R, Bates DW, Landrigan C, McKenna KJ, Clapp MD, Federico F, et al. Medication errors and adverse drug events in pediatric inpatients. JAMA. 2001;285(16):2114-20.

4. Wang JK, Herzog NS, Kaushal R, Park C, Mochizuki C, Weingarten SR. Prevention of pediatric medication errors by hospital pharmacists and the potential benefit of computerized physician order entry. Pediatrics. 2007;119(1):e77-85.

5. Alagha $\mathrm{HZ}$, Badary OA, Ibrahim HM, Sabri NA. Reducing prescribing errors in the paediatric intensive care unit: an experience from Egypt. Acta Paediatr. 2011;100(10):e169-74.

6. Elden NMK, Ismail A. The importance of medication errors reporting in improving the quality of clinical care services. Glob J Health Sci. 2015;8(8):243.

7. Kaushal R, Bates DW, Landrigan C, McKenna KJ, Clapp MD, Federico F, et al. Medication errors and adverse drug events in pediatric inpatients. J Am Med Assoc. 2001;285(16):2114-20.

8. Cunningham KJ. Analysis of clinical interventions and the impact of pediatric pharmacists on medication error prevention in a teaching hospital. J Pediatr Pharmacol Ther. 2012;17(4):365-73.

9. Alomi YA. National Medication Safety Program at Ministry of Health in Saudi Arabia. J Pharmacovigil. 2015;3(5):e145.

10. The Joint Commission. 2016 Comprehensive Accreditation Manuals. Joint Commission Resources, Spi Lslf edition. 2016. Available from: https://www. jointcommission.org/standards_information/edition.aspx.

11. Medication Management (MM). In: National Hospital Standards. $2^{\text {nd }}$ Editio. Saudi Central Board for Accreditation of Healthcare Institutions. 2015;194-211.

12. Institute for Safe Medication Practices. Medication Safety Self Assessment ${ }^{\text {t }}$ for Community/Ambulatory Pharmacy. 2017. Available from: https://www. ismp.org/assessments/community-ambulatory-pharmacy.

13. Institute for Safe Medication Practices. Medication Safety Self Assessment for Hospitals, Key Definitions. 2011. Available from: http://ismp.org/ 
Alomi, et al:: Pharmacist Intervention and Prevention Medication Errors in in East Province, Saudi Arabia

selfassessments/Hospital/2011/definitions.pdf.

14. Institute for Safe Medication Practices. Medication Safety Self Assessment ${ }^{\circledast}$ for Oncology. 2012. Available from: https://www.ismp.org/ assessments/international-oncology.

15. Conners J, Dager W, Evan M, Gulseth M, Jenkins RWM. 2017 ISMP Medication Safety Self Assessment for Antithrombotic Therapy. Medication
Management (MM). In: National Hospital Standards. $2^{\text {nd }}$ Edition. Saudi Central Board for Accreditation of Healthcare Institutions. 2015;194-211.

16. Saudi Center Board for Accreditation for Healthcare Institutions (CBAHI). Medication Management (MM). In: National Hospital Standards. $2^{\text {nd }}$ Edition. 2016;194-211.

Cite this article as: Alanazi AA, Alomi YA, Almaznai MM, Aldwihi M, Aloraifi IAK, Albusalih FA. Pharmacist's Intervention and Medication Errors Prevention at Pediatrics, Obstetrics and Gynecology Hospital in East Province, Saudi Arabia. Int J Pharmacol. Clin. Sci. 2019;8(2):122-8. 